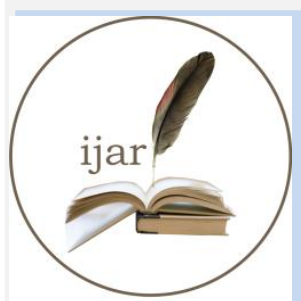

ISSN NO. 2320-5407

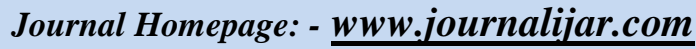 INTERNATIONAL JOURNAL OF ADVANCED RESEARCH (IJAR)}

Article DOI: $10.21474 / \mathrm{IJAR} 01 / 9228$

DOI URL: http://dx.doi.org/10.21474/IJAR01/9228

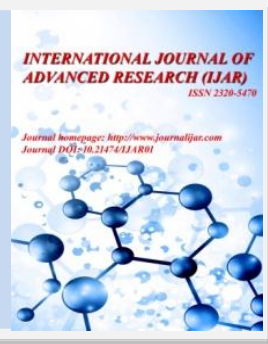

RESEARCH ARTICLE

\title{
PREVALENCE OF BRUCELLOSIS AMONG MEAT HANDLERS IN KARACHI, PAKISTAN.
}

\section{Fouzia Haider ${ }^{1}$, Hammad Ahmed ${ }^{1}$ and Manar Mohamad Ismail ${ }^{2}$.}

1. Department of Microbiology, University of Karachi, Pakistan.

2. Department of Laboratory Medicine, Faculty of Applied Medical Sciences, Umm Al Qura university, Makkah, Saudi Arabia.

\section{Manuscript Info}

.........................

Manuscript History

Received: 06 April 2019

Final Accepted: 08 May 2019

Published: June 2019

Key words: -

Brucellosis, Meat handlers, Abattoir workers, ELISA

\section{Abstract}

This study was designed to determine the prevalence of brucellosis among meat handlers in Karachi, Pakistan. The presence of IgM and IgG antibodies against Brucellae species in the serum samples of 72 meat handlers from different slaughter houses were determined by ELISA. The prevalence of brucellosis in 12 out of 72 samples was obtained. Out of 72 samples, 8 were positive for IgM and 4 were positive for IgG. The percent of positivity for IgM was $11.11 \%$ and the positivity for $\operatorname{IgG}$ was $5.5 \%$. The differential leucocyte count showed normal range of leucocytes in almost all of the samples except for two that had elevated number of basophils and that could be due to other physiological or pathological reasons.

This finding indicates a significant prevalence of brucellosis among meat handlers of seven slaughter houses of Karachi, Pakistan, which calls for a proper surveillance system and vaccination programs of the animals in order to control the transmission of the infection to healthy animals and subsequently preventing the human population from infection.

\section{Introduction:-}

Brucellosis is a zoonotic disease and endemic in many parts of the world. It is chronic infection in animals and can be transmitted to humans (Paulsen et al., 2002). Transmission of brucellosis is also documented from humans to humans (Tuon et al., 2017). Brucellae, the causative agents of brucellosis, being intracellular parasites are protected from host defenses and chemotherapeutic agents (Nicoletti., 2010). Brucellae are highly significant being categorized as biological agents due to their high contagiousness and their impact on human and animal health (Gwida et al., 2010) unfortunately brucellosis is one of the neglected health problems (Frank et al., 2018).

Three main species of Brucellae including Brucella abortus, Brucella suis and Brucella melitensis cause almost all the brucellosis infections in humans. Brucella melitensis causes $90 \%$ of human infections (Nicoletti., 2010). Brucellosis copies the actions of various multisystem diseases, which leads to misdiagnosis and treatment delays and in turn further increase in the complication rates (Buzgan et al., 2010). 
About 500,000 cases of human brucellosis are reported annually (Gwida et al., 2010). The infection prevalence is more than 10/100,000 populations in some endemic countries (Buzgan et al., 2010). The true rates of brucellosis in endemic countries are probably higher than reported due to deficiencies in the techniques of diagnosis. There is a huge economic loss by the Brucella infection in humans. The reasons behind these economic losses are long term treatment, loss of working personnel due to infection, decrease in income and cost of drugs. The disease is more common in countries with poorly standardized animal and public health programs (Capasso., 2002). The measures should be implemented by the government in the control of brucellosis and in different eradication programs such as routine checkup of the animals by serological tests and vaccination should be done in the cattle farms. Thus preventing the disease in animals and onward transmission to humans (FAO Animal production and health division., 2010; Bernard., 2010).

The principle routes for transmission are occupational exposure, person to person contact, infection from a contaminated environment, inhalation and food-borne transmission (Malik., 1997; Corbel., 2006). Brucellosis infection by meat and meat products is less frequently common because it is not usually eaten raw. However, people dealing with livestock or their products e.g. farmers and abattoir workers are at highest occupational risk (Al Shamahy., 2000). Human Brucella seroprevalence is reported from various parts of the world among abattoir personnel 5.6\% from Cameroon (Awah-Ndukum et al., 2018), 4.7\% from Ethiopia (Tsegay., 2017), 24.1\% from Abuja Nigeria (Aworh et al., 2013). 4.0\% among abattoir workers in Saudi Arabia (Al sekai., 1993). Due to paucity of epidemiological data of human brucellosis among abattoir in the region of the study, this research focused on the prevalence of brucellosis among individuals involved in handling meat in Karachi, Pakistan.

\section{Study design}

A modified cross-sectional study design was used to find out the prevalence of brucellosis in meat handlers in seven different slaughter houses in Karachi. These seven slaughter houses include: Empress Meat market, Sadar; Liaquatabad meat market; New Karachi meat market; Gulberg meat market; Water pump meat market; Al - Noor meat market and Gulshan -e -Iqbal meat market. Blood samples of meat handlers were collected and all the information was collected on a predesigned questionnaire from each volunteer.

\section{Collection of blood samples}

Five $\mathrm{ml}$ of blood was collected in serum tube under complete aseptic conditions. The tubes were transported in ice box without shaking to prevent red cell hemolysis. The samples were centrifuged at 2500 rpm for 15-20 minutes to separate the serum that was collected and stored at $4^{\circ} \mathrm{C}$ until used.

\section{Relative differential count of the blood leukocytes}

Differential count of the collected samples was done by Field's staining method.

\section{Detection of anti-Brucella antibodies (IgG and IgM) by ELISA:}

Serion ELISA classic Brucella IgG/IgM test kits (würzburg, Germany) were used in the present study. Serum samples were diluted and the test was performed according to the manufacturer's instruction. The results were interpreted as positive and negative as the aim of the study was to detect the prevalence rate.

\section{Statistical methods}

The data were analyzed using SPSS program version 20. Quantitative data were presented as the mean \pm SD or median ( $\min -\max )$ and range as appropriate. Categorical data were presented as frequency and percentage. Comparison between two groups was conducted using Student's t-test, and nonparametric Mann-Whitney U and Kruskal-Wallis tests were used for the data that were not normally distributed. A chi-square or Fisher's exact test was used for comparisons between qualitative data as appropriate. A two-sided alpha value was set at 0.05 . Probability (P-value) $<0.05$ and $<0.001$ were considered significant and highly significant, respectively.

\section{Results}

Prevalence of anti- brucella antibodies

This study included 72 participants from seven slaughter houses. Out of total 72 samples, $8(11.1 \%)$ were positive for IgM antibodies and $4(5.5 \%)$ were positive for IgG antibodies. no single sample showed double positivity for IgG and IgM. Data are presented in Table 1 
Table 1:- Test results of IgG and IgM by ELISA method

\begin{tabular}{|l|l|l|l|l|}
\hline & $\begin{array}{l}\text { Number of } \\
\text { samples }\end{array}$ & Mean \pm SD & Median (min-max) & Positivity no (\%) \\
\hline IgM & 72 & $0.21 \pm 0.29$ & $0.11(0.0-1.08)$ & $8(11.1 \%)$ \\
\hline IgG & 71 & $0.07 \pm 0.14$ & $0.02(0.001-0.63)$ & $4(5.5 \%)$ \\
\hline
\end{tabular}

Age distribution among the positive cases:

None of the positive cases for either IgM or IgG were above the age of 45 years. Regarding the IgM positive cases, 4 cases were detected in the age group 15-25, 3 cases in 26-35 groups and one case in the 36-45 group. Despite the prevalence of positivity among the younger age groups, no significance could be reached, $p$ value 0.3 . The $\operatorname{IgG}$ positive samples were distributed as follow; 2 cases in the age group 15-26 and one case in both 26-35 and 36-45 groups, without significant difference in this distribution, $\mathrm{P}$ value 0.7. Data are shown in Table 2.

Table 2: Age distribution of the positive samples

\begin{tabular}{|c|c|c|c|c|c|c|c|}
\hline & \multicolumn{5}{|c|}{ Age } & \multirow[t]{2}{*}{$\mathrm{P}$ value } \\
\hline & & $15-25$ & $26-35$ & $36-45$ & $46-55$ & $56-65$ & \\
\hline \multirow{2}{*}{$\operatorname{IgM}$} & Positive $(\mathrm{n}=8)$ & 4 & 3 & 1 & 0 & 0 & \multirow{2}{*}{0.3} \\
\hline & Negative $(n=64)$ & 15 & 18 & 16 & 12 & 3 & \\
\hline \multirow{2}{*}{$\operatorname{IgG}$} & Positive $(n=4)$ & 2 & 1 & 1 & 0 & 0 & \multirow{2}{*}{0.7} \\
\hline & Negative $(\mathrm{n}=67)$ & 17 & 19 & 16 & 12 & 3 & \\
\hline
\end{tabular}

\section{Differential white cell count}

There was no significant difference between the IgM positive and negative regarding the neutrophils, lymphocytes, monocytes or eosinophils counts, $\mathrm{P}$ value $>0.05$. There was a significant relative increase in the basophiles count in the IgM positive samples, $\mathrm{P}$ value 0.02 . However, these data are within the normal range and has no clinical significance. Data are shown in Table 3.

Table 3: Comparison of differential white cell count between IgM positive and negative samples.

\begin{tabular}{|l|c|c|c|}
\hline & $\begin{array}{c}\text { IgM positive } \\
\mathrm{n}=8\end{array}$ & $\begin{array}{c}\text { IgM negative } \\
\mathrm{n}=64\end{array}$ & P value \\
\hline Neutrophils & $61.7 \pm 5.4$ & $59.2 \pm 8.7$ & 0.4 \\
\hline Lymphocytes & $29.0 \pm 4.0$ & $30.6 \pm 5.9$ & 0.4 \\
\hline Monocytes & $4.8 \pm 1.3$ & $5.1 \pm 0.8$ & 0.5 \\
\hline Eosinophils & $2.8 \pm 0.6$ & $3.3 \pm 0.9$ & 0.2 \\
\hline Basophiles & $1.5 \pm 1.1$ & $0.75 \pm 0.8$ & $0.02^{*}$ \\
\hline
\end{tabular}

Comparison of differential white cell count between the participants that showed IgG positivity with the negative samples reveals no significant differences, $\mathrm{P}$ value $>0.05$. Data are shown in Table 4.

Table 4: Comparison of differential white cell count between IgG positive and negative samples.

\begin{tabular}{|l|c|c|c|}
\hline & $\begin{array}{c}\text { IgG positive } \\
\mathrm{n}=4\end{array}$ & $\begin{array}{c}\text { IgG negative } \\
\mathrm{n}=67\end{array}$ & P value \\
\hline Neutrophils & $59.7 \pm 3.2$ & $59.5 \pm 8.7$ & 0.9 \\
\hline Lymphocytes & $30.0 \pm 2.7$ & $30.4 \pm 5.9$ & 0.8 \\
\hline Monocytes & $5.7 \pm 0.5$ & $5.0 \pm 0.9$ & 0.15 \\
\hline Eosinophils & $3.2 \pm 1.2$ & $3.2 \pm 0.9$ & 0.9 \\
\hline Basophiles & $1.2 \pm 0.5$ & $0.8 \pm 0.9$ & 0.3 \\
\hline
\end{tabular}

\section{Discussion:-}

The emergence or re-emergence of zoonosis takes place worldwide. One way towards the eradication is the elimination of the infected animal reservoirs (Tun., 2007). Humans may get infected from direct or indirect contact with the zoonotic contaminated products. Accordingly, strict precautionary measures should be taken to prevent the exposure of humans to the zoonotic agents. The control of human and animal brucellosis is considered a major international priority for medical and veterinary doctors (Tun., 2007). Majority of human brucellosis (90\%) are 
caused by Brucella melitensis. However, other species such as Brucella abortus, Brucella suis, Brucella inopinata and Brucella canis contribute to this health problem (Godfroid et al., 2011).

The main objective of this study was to determine the prevalence of brucellosis among a high-risk population; meat handlers in different slaughter houses of Karachi, Pakistan.

This study included 72 participants, among this group $11.11 \%$ were tested positive for Brucellae IgM antibodies and $5.55 \%$ were tested positive for Brucellae IgG antibodies. The monitoring of antibodies gives an indication of the status of the infection. During the first few days of acute infection, IgM is the only antibody that could be detected and its level continues to elevate, generally decreasing after 2-3 months. However, in some cases IgM antibodies can persist for several months (Basappa et al., 2010). In our study, we investigated the positive IgM cases for the presence of any symptoms suggestive of acute Brucella illness; fever, back pain, headache, night sweats, poor appetite, weight loss or weakness. Only two cases had a suggestive symptom of the disease that would alert attention towards the subclinical infection and emphasize the importance of serological testing in detecting infected cases, rather than depending on the clinical picture only, where the possibility of misdiagnosis by physicians may lead to a long debilitating illness. IgG titer is the parameter used for the detection of chronic brucellosis where it is produced for an extended period (Basappa et al., 2010). Only one case out of the IgG seropositive cases experienced brucellosis symptoms.

In this study, we detected a higher percentage of acute cases than that of chronic infection in accordance to a previous study (Buzgan et.al., 2010).

The range of positive cases of human brucellosis varies widely, from $<0.01$ to $>200$ per 100,000 population in Asian countries (Tun., 2007). Accordingly, our recorded percentages were very high. This high prevalence rate could be due to the occupation risk factor where the meat handlers deal with cattle and meat, which are the primary hosts of the pathogen, and can catch the brucella infection easily. Similarly, a study from Africa reported $5.2 \%$ prevalence rate of brucellosis among 500 occupationally high-risk group in North- Eastern part of Nigeria (Baba et al 2001). However, another study from Abuja, Nigeria reported seroprevalence rate of $24.1 \%$ (Aworh et al., 2013). Back to prevalence rates of brucellosis in Asia, reports from Bangladesh stated 2.5\% seropositivity among butchers, 2.6$21.6 \%$ among farmers, and 5.3-11.1\% among veterinarians where all these were among high risk groups due to direct contact with the animals and their products such as consumption of raw milk (Islam et al., 2013). The prevalence of bovine Brucellosis in Indonesia and Thailand is 1-2\% and ranges from 4-5\% in Malaysia and Myanmar (Bamaiyi et al., 2014). From these reports, it is obvious that the seroprevalence rate is different among different countries and even in different provinces in the same country. Furthermore, the rate is also variable according to the risk factors and the local habits of each community that make it essential to study these rates following a national program. The evaluation of this problem could be a national essentiality to find a suitable solution where the "test and slaughter" strategy with compensation could be a major economic burden for a country with a high prevalence rate and high number of cattle heads. On the other hand, vaccinations following strict safety measures could be a perfect solution for such situations. However, decision making to overcome a health problem directly connected to the economy needs propagation of the study to include many provinces of the country and a large number of human participants and animal samples.

With regards to the differential leukocyte count of the study population, all the results were within normal range except for higher percentage of basophiles in the IgM seropositive group compared to the seronegative group. However, this finding is clinically irrelevant because the disease is usually associated with anemia, thrombocytopenia and leukopenia (Akdeniz et al., 1998). where neutropenia and lymphopenia are also a common finding (Crosby et al., 1984).

\section{Limitation of the study:}

This study was conducted in a single city and cannot be generalized in regards to the whole country. The study also included one category of occupational high risk groups; the meat handlers.

\section{Recommendations}

This study is just an alarm for the prevalence state of brucellosis that should be extended over a larger geographical area of the country with a wider range of the study population to include farmers, butchers, and veterinarians. Animal samples should also be included. Such a study would enable the authorities to apply the proper measures to 
control the transmission of the infection to healthy animals, and subsequently to humans, that could include surveillance and vaccination.

\section{References:-}

1. Akdeniz H, Irmak H, Seçkinli T, Buzgan T, Demiröz AP. (1998). Hematological manifestations in brucellosis cases in Turkey Acta Med Okayama. Feb;52(1):63-5.

2. Al-Sekai, M A.(1993). Prevalence of brucellosis among abattoir workers in Saudi Arabia. J. of the Royal Society of Health, 113: 5: 230-233

3. Al-Shamahy HA, Whitty CJ, Wright SG. (2000) Risk factors for human brucellosis in Yemen: a case control study. Epidemiol Infect. 125(2):309-13. pmid:11117954

4. Awah-Ndukum, J., Mouiche, M., Kouonmo-Ngnoyum, L., Bayang, H. N., Manchang, T. K., Poueme, R., ... Zoli, A. P. (2018). Seroprevalence and risk factors of brucellosis among slaughtered indigenous cattle, abattoir personnel and pregnant women in Ngaoundéré, Cameroon. BMC infectious diseases, 18(1), 611. doi:10.1186/s12879-018-3522-x

5. Aworh MK, Okolocha E, Kwaga J, Fasina F, Lazarus D, Suleman I, Poggensee G, Nguku P, Nsubuga P (2013) Human brucellosis: seroprevalence and associated exposure factors among abattoir workers in Abuja, Nigeria 2011. Pan Afr Med J. 17;16:103. doi: 10.11604/pamj.2013.16.103.2143. eCollection 2013.

6. Baba MM, Sarkindared SE, Brisibe F. Serological evidence of brucellosis among predisposed patients with pyrexia of unknown origin in the north eastern Nigeria (2001). Central European J Public Hlth.3:158-161.

7. Bamaiyi PH, Hassan L, Khairani-Bejo S, Zainal Abidin M (2014). Up- dates on Brucellosis in Malaysia and south Asia Mal J Vet Res. 5:71-82

8. Buzgan T, Karahocagil MK, Irmak H, Baran AI, Karsen H, et al. (2010) Clinical manifestations and complications in 1028 cases of brucellosis: a retrospective evaluation and review of the literature. Int J Infect Dis 14: e469-e478

9. Basappa., A. Paranda, S. Amarnath, G. Patil et al. (2010). ELISA versus convential methods of diagnosing endemic brucellosis. Am. J. Trop. Med. Hyg. 83(2): 314-318.

10. Bernard valet. (2010). Improving animal health worldwide is a priority. Available from: URL: http://www.oie.int/eng/Edito/en_edito_juil 07. html.

11. Capasso. L. (2002. Bacteria in two-millennia-old cheese and related epizoonoses in Roman populations. J of Infection. 45 (2): 122-127.

12. Corbel, M. J. 2006. Brucellosis in humans and animals. Geneva (Switzerland): world health organization

13. Crosby E, Llosa L, Miro Quesada M, Carrillo C, Gotuzzo E. (1984).Hematologic changes in brucellosis . J Infect Dis. 150(3):419-24

14. FAO. 2010. Animal production and health division. Animal health disease cards Brucellosis Ovine/ Carpine. Available from: http://www.fao.org/ag/ag ainfo/subjects/en/health/disease-cards/brucollosis-ov.html

15. Franc KA, Krecek RC, Häsler BN, Arenas-Gamboa AM (2018). Brucellosis remains a neglected disease in the developing world: a call for interdisciplinary action. BMC Public Health. 18:125. pmid:29325516

16. Godfroid, J., H. C. Scholz, T. Barbier, C. Nicolas, P. Wattiau, D. Fretin, A. M. Whatmore, A. Cloeckaert, J. M. Blasco, I. Moriyon, C. Saegerman, J. B. Muma, S. Al Dahouk, H. Neubauer and J. J. Letesson (2011). Brucellosis at the animal/ ecosystem/ human interface at the beginning of the $21^{\text {st }}$ century. Preventive Veterinary Medicine; 102: 118-131.

17. Gwida, M., S. Al-Dahouk, F. Melzer, U. Rosler, H. Neubauer and H. Tomaso (2010). Brucellosis - Regionally emerging zoonotic disease? Croat. Med. J. 51: 289-95

18. Islam MA, Khatun MM, Werre SR, Sriranganathan N, Boyle SM (2013). A review of Brucella seroprevalence among humans and animals in Bangladesh with special emphasis on epidemiology, risk factors and control opportunities. Vet Microbiol. 2013 Oct 25;166(3-4):317-26. doi: 10.1016/j.vetmic.2013.06.014. Epub 2013 Jun 29

19. Malik, G. M. (1997). A clinical study of brucellosis in adults in the Asir region of Southern Saudia Arabia. Am. J. Trop. Med. Hyg. 56: 375-377

20. Nicoletti, P (2010). Brucellosis: Past, present and future. Contributions. Sec. Biol. Med. Sci. MASA. XXXI. 1: 21-32

21. Paulsen, I. T., R. Seshadri, K. E. Nelson, J. A. Eisen, J. F. Heidelberg, T. D. Read, R. J. Johnson and C. M. Fraser (2002). The Brucella suis genome reveals fundamental similarities between animal and plant pathogens and symbionts. PNAS; 99 (20): 13148-13153. 
22. Tsegay, A., Tuli, G., Kassa, T. et al. (2017) Seroprevalence and risk factors of brucellosis in abattoir workers at Debre Zeit and Modjo export abattoir, Central Ethiopia BMC Infect Dis. 17: 101. doi.org/10.1186/s12879-0172208-0

23. Tun, T. N. (2007). Prevalence survey of bovine brucellosis (Brucella abortus) in dairy cattle in Yangon, Myanmar. Dissertation for Award of MSc Degree at Chiang Mai University and Freie University at Berlin. $137 \mathrm{pp}$.

24. Tuon FF, Gondolfo RB, Cerchiari N (2017). Human-to-human transmission of Brucella - a systematic review. Trop Med Int Health. 22(5):539-546. doi: 10.1111/tmi.12856. Epub 2017 Mar 9. 